\title{
Model predictive control applied to residential self-assisted ground source heat pumps
}

\section{Alex Laferrière}

\section{ABSTRACT}

The seasonal performance and feasibility of a "self-assisted" ground source heat pump system are examined. The system uses an electric heating element to inject heat into the ground and reduce peake energy demand by eliminating the need for auxiliary heating. Doing so allows for an undersized borehole to be used with a smaller penalty on peak power consumption. A simulation model for an energy efficient residential building in the Montreal area is implemented in the Modelica language. A model predictive control strategy with a week-long prediction horizon is applied to determine the optimal heat injection rate and timing for the electric heating element. The model uses an improved cell shifting load aggregation scheme for ground temperature predictions. On a borehole that is undersized by $16.7 \%$, the self-assisted configuration with model predictive control reduces peak energy demand by $58 \%$ over a 5 year period, with an increase in total annual energy consumption of $2.8 \%$ when compared to an unassisted configuration.

\section{INTRODUCTION}

Ground source heat pump (GSHPs) systems are an increasingly popular method of heating and cooling residential buildings, in large part thanks to their low energy consumption. When used in cold climates, where yearly building heating demand can be significantly larger than the yearly building cooling demand, ground temperatures in the vicinity of the geothermal boreholes will gradually decrease. Low ground temperatures translate into low returning fluid temperatures from the geothermal boreholes and thus have a negative influence on the efficiency of GSHPs in heating operation. When there is a large heating demand for a sufficient amount of time, returning fluid temperatures may reach a lower threshold where the heat pump may no longer safely operate. In these cases, auxiliary heating (e.g. electric heating) is necessary to meet the building heating demand, creating a peak in the system's energy consumption and thereby hindering the competitiveness of GSHPs. Peak heating loads also create additional constraints on the design of geothermal systems by increasing the required borehole length at a great financial cost.

It is possible to assist GSHPs by implementing additional energy sources, which will recharge the ground thermal energy stores and raise ground temperatures. By strategically injecting heat into the ground from an auxiliary source, returning fluid temperatures may be kept above the lower operating limit, thus limiting the need for auxiliary heating at times of peak heating demand and reducing the penalty on undersized boreholes. A common strategy to assist GSHPs is to have solar thermal collectors coupled to the GSHPs. Among other methods of coupling solar energy to GSHPs, Han, et al. (2008) found improvements for systems in colder climates by using latent heat energy storage with an 
additional ground circuit. Kjellsson, et al. (2010) tested different configurations with storage tanks connected to solar collectors and water heating systems. Eslami-nejad and Bernier (2011) found a substantial decrease in required borehole length by using an independent double U-tube configuration where solar heat is injected in a secondary circuit. More recently, Eslami Nejad, et al. (2017) proposed a new "self-assisted" heat pump configuration where the heat pump injects heat in a secondary ground loop prior to predicted peak heating loads which resulted in a decrease in peak power consumption with little increase in energy consumption.

A simulation model for a GSHP controlled using model predictive control (MPC) is developed to further study the feasibility of a modified "self-assisted" configuration for GSHPs operating in cold climates. Recent research has shown that different types of MPC can offer improved building energy performance compared to other control techniques - such as standard rule-based control laws - in a wide array of different applications (Afram and JanabiSharifi 2014; Oldewurtel, et al. 2012; Shaikh, et al. 2014).

Figure 1 shows a schematic of the modified self-assisted GSHP system used in this study. The system uses a single closed-loop vertical borehole coupled to a water-to-air single speed heat pump in a single-family house. An electric heating element at the point of fluid reentry into the borehole injects heat into the ground. The model predictive controller used in the simulation model uses future ambient temperatures to regulate this heating element. The controller minimizes the peak electrical consumption of the GSHP by determining the amount of heat to be injected into the ground and the optimal timing in which to do so. The use of MPC allows this optimization to be done while limiting the increase of the GSHP energy consumption due to the use of the electric heating element. The impact of the heat injection over a 5 year period is examined on an undersized borehole, and is also compared with the fully sized borehole. The simulation model (including the building, the heat pump, the borehole, the heating elements and the controllers) is constructed with components created using the Modelica language with the IBPSA library (Wetter, et al. 2015).

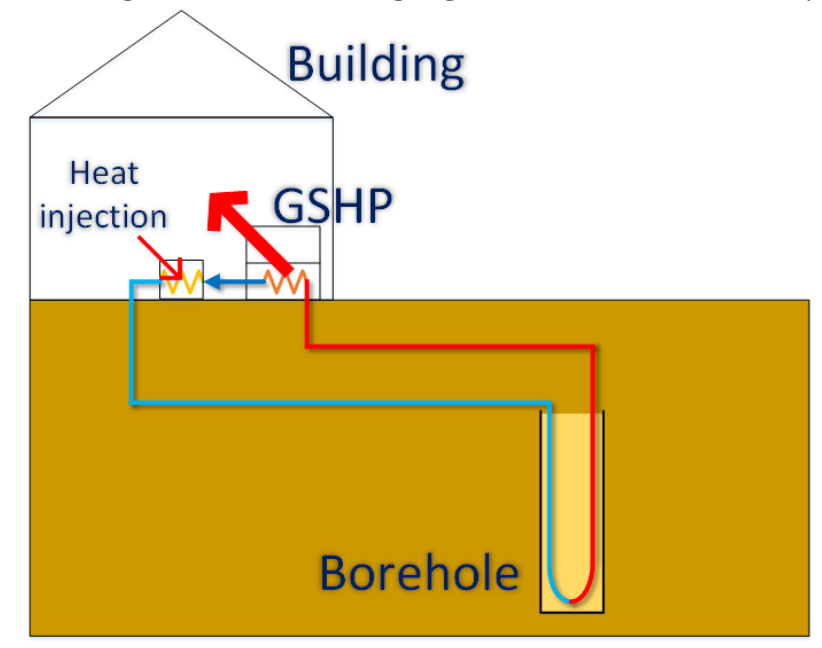

Figure 1 Self-assisted ground-source heat pump system

\section{SIMULATION MODEL}

\section{Building Component}

The building is modeled as a single zone building with thermal resistances defined by the NovoClimat building energy performance standard (Transition Énergétique Québec, 2017). This standard defines a set of minimum thermal resistances for the building's various surfaces as well as maximum air inflitration rate and refers to the local ENERGY 
STAR standard for window UA values. Solar heat gains are neglected in the simulation model. The resulting total thermal resistance of the building to the exterior air is $0.00786 \mathrm{~K} / \mathrm{W}$. Occupancy-related heat gains are modeled by an average occupancy gain schedule proposed by Hendron (2005):

$$
Q_{\text {int }}=Q_{\max } *\left\{\begin{array}{cc}
1 & 19: 00 \leq t \leq 8: 00 \\
0.25 & 8: 00 \leq t \leq 19: 00
\end{array}\right.
$$

The value used for maximum occupancy-related heat gains $\left(\mathrm{Q}_{\max }\right)$, assuming an average of 2.5 occupants per residence, is $725 \mathrm{~W}$ and is evaluated following an ASHRAE (2013) method to estimate total residential heat gains.

$$
Q_{\text {max }}=Q_{\text {latent }}+Q_{\text {sensible }}=156+2.42\left(200 \mathrm{~m}^{2}\right)+34(2.5 \text { occupants })=725 \mathrm{~W}
$$

\section{Heat Pump Component}

A simulation model for a fully reversible water-to-air heat pump is implemented. The source-side temperature dependence of the heating and cooling coefficient of performance (COP) and capacity is represented by second degree polynomial correlations. The correlation coefficients are evaluated by a fitting procedure on performance data from a commercial geothermal heat pump with a nominal capacity of $7.6 \mathrm{~kW}$ and a source-side nominal mass flow rate of $0.38 \mathrm{~kg} / \mathrm{s}$. This mass flow rate is assumed to be an average operational value at which the heat pump capacity and COP are evaluated. The entering air temperature is the indoor temperature, and its variations are considered to have negligible effect on the capacity or COP. The resulting capacity and COP curves are shown in Figure 2.

The heat pump in the present study can also operate at partial load, in which case the part load ratio (PLR) will be lower than 1 and will linearly impact the heat being added or substracted to the building air. When operating at partial load, a part load factor (PLF) is calculated to determine the resulting COP using the rational expression shown in Equation 3. The coefficients are those given by Henderson, et al. (1999) for what they describe as a "good AC" in regards to energy performance, with the same part load coefficients also being recommended for heating performance. The PLF's impact on the COP is shown in Equation 4.

$$
\begin{gathered}
\mathrm{PLF}=\frac{\mathrm{PLR}}{0.00988125+1.08033 \cdot \mathrm{PLR}-0.105267 \cdot \mathrm{PLR}^{2}+0.0151403 \cdot \mathrm{PLR}^{3}} \\
\mathrm{COP}_{\text {part load }}=\min \left(1, \mathrm{PLF} * \mathrm{COP}_{\text {full load }}\right)
\end{gathered}
$$
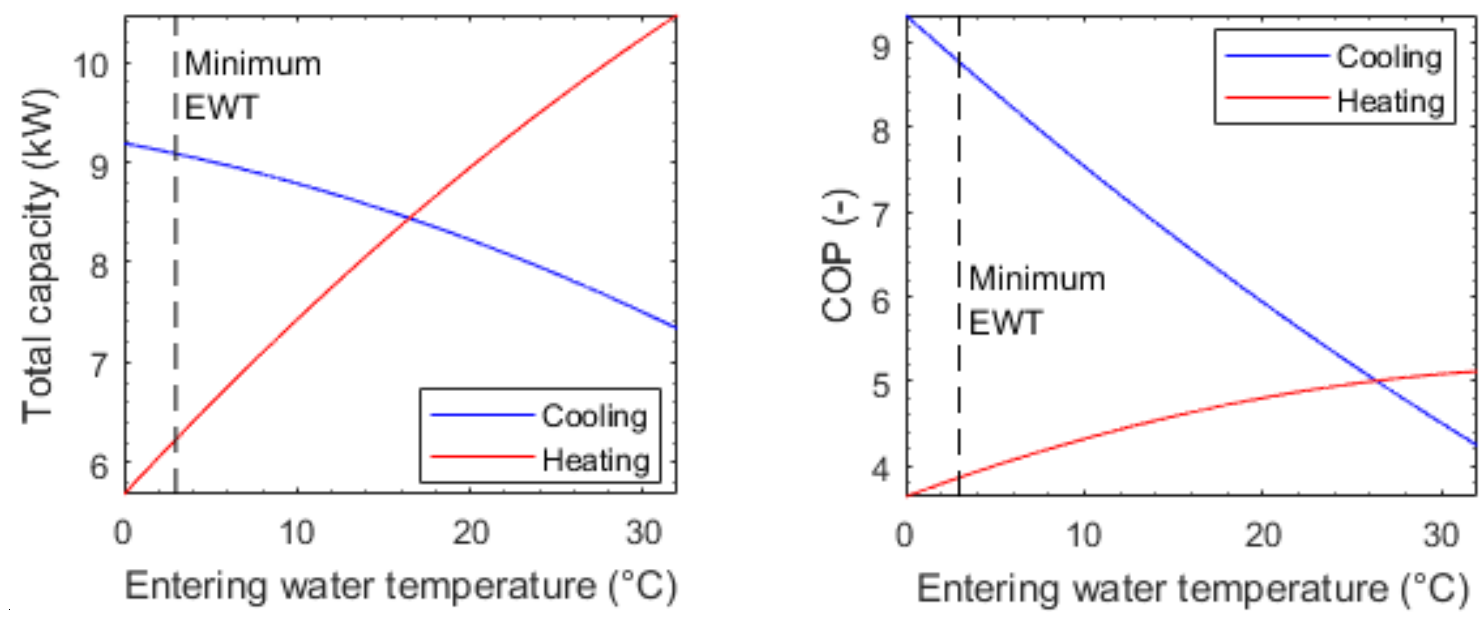

Figure 2 Source-side temperature dependence of heat pump capacity (left) and COP (right) 
Using a PLR and a PLF in such a way means that the behaviour of the heat pump (including its on-off cycles) is represented as a mean operational value which globally accounts for performance losses that occur when turning the heat pump on or off. In the simulation model, the PLR applied to the heat pump is calculated at every time step according to the following procedure:

1. If the current indoor temperature is outside of the temperature setpoint interval (i.e. $21^{\circ} \mathrm{C}$ for heating and $25^{\circ} \mathrm{C}$ for cooling, with a $\pm 0.25^{\circ} \mathrm{C}$ interval for both bounds) and the heat pump can operate at the current source-side entering water temperature, the heat pump operates at full capacity.

2. When the indoor temperature is within the set point range, the net building heat loss or gain is used to dertermine the required PLR (with a maximum of 1) and maintain the zone temperature constant.

3. If the heat pump is unable to adequately heat the building and the indoor temperature falls to $20^{\circ} \mathrm{C}$, an auxiliary electric heating system is triggered and its average heating power is modulated to maintain the indoor temperature at the auxiliary set point of $20^{\circ} \mathrm{C}$.

The activation of the auxiliary electric heating can be required when the heat pump's source-side inlet temperature falls below its lower limit of $3^{\circ} \mathrm{C}$, which forces it to shut off. This limit ensures that, in heating mode, the leaving water temperature is always above $0^{\circ} \mathrm{C}$. The maximum inlet temperature is $32.2^{\circ} \mathrm{C}$. Whenever the inlet temperature falls below the minimum operating value, the heat pump is not turned on until the temperature has risen to at least $4.5^{\circ} \mathrm{C}$.

\section{Borefield Component}

Component Parameters and Borehole Resistance. The component uses an external file containing a timeseries describing the borefield's thermal response factor as an input. This thermal response factor links the temperature change at the borehole wall with the ground heating load, and is applied between the borehole wall and the undisturbed ground. The heat transfer between the heat carrier fluid and the borehole wall is modeled using 10 evenly sized borehole segments. Each segment has the same borehole resistance between its local fluid temperature and the borehole wall temperature (the latter being the same for all 10 segments).

Improved Load Aggregation Scheme. To greatly reduce calculation times during simulations, a load aggregation scheme is used based on that of Claesson and Javed (2012). This scheme must however be adapted due to the way the Modelica solver handles events. During a simulation, the solver will attempt to determine when a conditional event is triggered and will automatically create additional time steps around the time of the event. This allows for conditional statements to be integrated very easily in the system, as there is no need to modify the solver's calculation time step to account for it. However, it also means that it is difficult to control the solver's time steps. Thus, modifications to the load aggregation scheme are proposed to handle the variable time steps. At every aggregation time step $t_{k}=t_{k-1}+\Delta t_{a g g}$, temporal superposition is used to predict the borehole wall temperature at the next aggregation step, assuming no heat is extracted over the interval $t_{k} \leq t \leq t_{k+1}$. At every simulation time during this interval, the borehole wall temperature is evaluated by adding the contribution of heat transfered before and after the aggregation time $t_{k}$ :

$$
\begin{gathered}
T_{b}(t)-T_{g}=\int_{0}^{t_{k}} Q(\tau) \frac{d h}{d \tau}(t-\tau) d \tau+\int_{t_{k}}^{t} Q(\tau) \frac{d h}{d \tau}(t-\tau) \mathrm{d} \tau \\
\Delta T_{b}(t)=\Delta T_{b}^{*}(t)+\Delta T_{b, q}(t)
\end{gathered}
$$

where $T_{b}$ is the borehole wall temperature, $T_{g}$ is the undisturbed ground temperature, $Q$ is the heat extraction rate per unit borehole length and $h=g / 2 \pi k_{s}$ is the temperature response factor. $g$ is the g-function proposed by Eskilson (1987), a dimensionless parameter to characterize the temporal change in the thermal response of a borefield. 
The borehole wall temperature increase assuming no heat extraction $\Delta T_{b}^{*}$ can be rewritten for discrete aggregation time steps $\Delta t_{a g g}$ according to the load aggregation scheme of Claesson and Javed (2012). At the time corresponding to the next aggregation step $t_{k+1}$ :

$$
\Delta T_{b}^{*}\left(t_{k+1}\right)=\sum_{p=2}^{N_{a g g}} \bar{Q}_{p} \cdot \Delta h\left(t_{p}\right)
$$

where $\Delta h\left(t_{p}\right)$ is the thermal response factor increment from $t_{p-1}$ to $t_{p}, \bar{Q}_{p}$ is the average heat transfer rate in aggregation cell $p$. An advantage of using Modelica is that expressions may explicitely use time derivatives of variables when building equations, as the time derivatives of all of the variables used in the system of equations are calculated numerically. In the absence of heat extraction during an interval $t_{k} \leq t \leq t_{k+1}$, it is assumed that the borehole wall temperature drop varies linearly between $\Delta T_{b}\left(t_{k}\right)$ and $\Delta T_{b}^{*}\left(t_{k+1}\right)$. Additionally, it is assumed that the temperature response factor varies linearly between $t=0$ and $t=\Delta t_{a g g}$. The time derivative of the borehole wall temperature drop is thus given by:

$$
\begin{gathered}
\Delta \dot{T}_{b}(t)=\Delta \dot{T}_{b}^{*}(t)+\Delta \dot{T}_{b, q}(t) \\
\Delta \dot{T}_{b}(t)=\frac{\Delta T_{b}^{*}\left(t_{k+1}\right)-\Delta T_{b}\left(t_{k}\right)}{\Delta t_{a g g}}+\frac{h\left(\Delta t_{\text {agg }}\right)}{\Delta t_{a g g}} Q(t)
\end{gathered}
$$

The modified load aggregation scheme is validated using the asymmetrical synthetic load profile proposed by Pinel (2003) over a 20 year simulation. The synthetic heating profile is shown for a single year in Figure 3 (where a positive load value indicates heat injected in the ground). Figure 4 shows the resulting borehole wall temperature over 20 years assuming an undisturbed ground temperature of $0^{\circ} \mathrm{C}$, while Figure 5 shows the absolute difference between the calculated borehole wall temperature and the exact value calculated by solving the temporal superposition in the spectral domain using fast Fourier transforms.

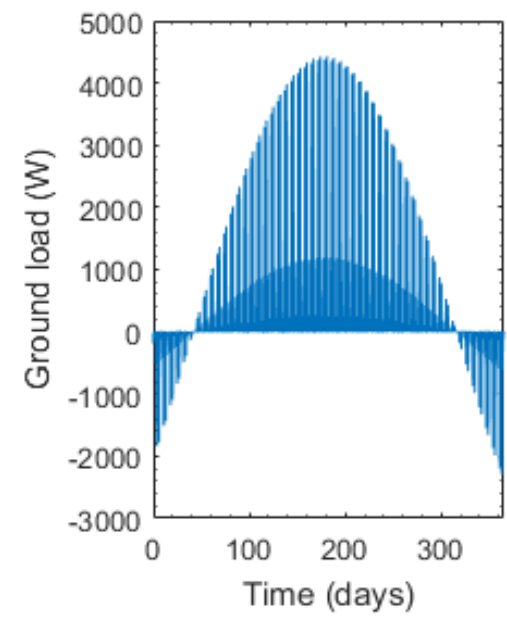

Figure 3 Synthetic load profile

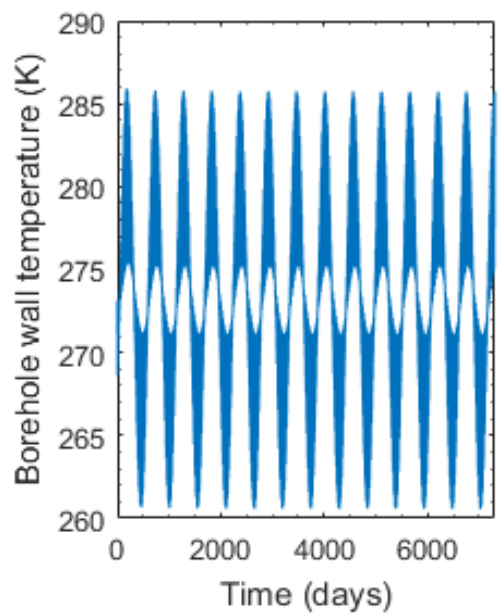

Figure 4 Borehole wall temperature

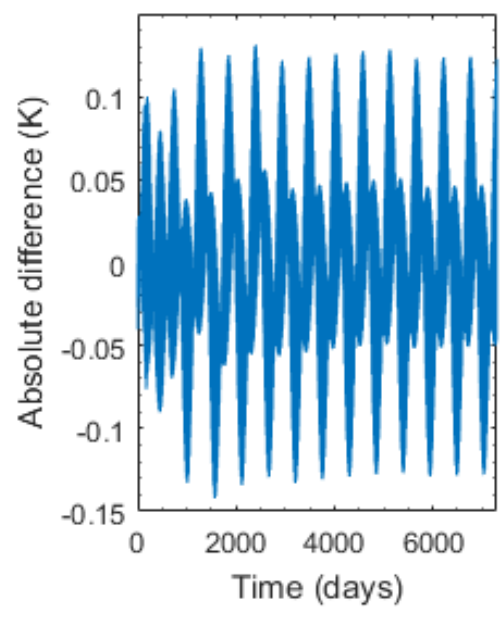

Figure 5 Absolute difference between new scheme and FFT solution 


\section{CONTROL STRATEGY}

The complete Modelica model with all three major components described in the previous section as well as the necessary controllers is simulated and optimized using the JModelica platform. Every controller decision relies on a constant receding horizon of 7 days without any forecast errors. This receding horizon is chosen to ensure that the controller can see far enough ahead to appropriately inject heat in the ground and to account for weather forecasts with a one-week forecast horizon. The duration of each heat injection period (along with the frequency at which a new decision to inject heat or not is taken) is 24 hours, which is chosen as a compromise between computation times and the accuracy of results. Every day in the simulation, an optimization problem of 7 different values of heat injection rate (one value per day in the receding horizon) must therefore be solved, after which only the first optimized value is kept. Between different simulations, temperatures, controller states and the averaged heat transfer rates $\bar{Q}_{p}$ in Equation 6 must be initialized with the values at the end of the first day of the previous simulation. The simulation itself has a nominal time step of 1 hour, though as described previously, in practice this is a maximum time step in Modelica.

A quadratic cost function is developed to account for the tradeoff between peak power and energy consumption:

$$
\begin{gathered}
C=P^{2}+\beta * E^{2} \\
\left\{\begin{array}{c}
E=\int_{0}^{t}\left(P_{H P}+P_{a u x}+P_{\text {inj }}\right) \mathrm{dt} \\
P=\max _{0 \leq t \leq t}\left(P_{H P}+P_{a u x}+P_{\text {inj }}\right)
\end{array}\right\}
\end{gathered}
$$

The three subscripts HP, aux and inj represent the heat pump power input, the auxiliary electric heating power and the power of the electric heat injection element, respectively. The maximum of their sum thus gives the peak power consumption $\mathrm{P}$ (measured in $\mathrm{W}$ in the previous equation), while their integral gives the total energy consumption $\mathrm{E}$ (measured in $\mathrm{kWh}$ in the previous equation). The remaining term $\beta$ is a parameter with a value of 1700 . This value was chosen using a case study of a single week for which $\beta$ was calculated with the goal of limiting the energy increase at $15 \%$ assuming the maximum peak power decrease (meaning that only the heat pump power is used) of $73.7 \%$ for that week. The optimization algorithm chosen to minimize this cost function is a particle swarm optimization, as this was found to have acceptable performance with a test case representing a single week while limiting the maximum number of function evaluations due to high computation times.

\section{RESULTS}

The simulation model and the control strategy shown previously are used on a residential building with a total floor area of $200 \mathrm{~m}^{2}$ and a GSHP with a single U-tube. The borehole's physical characteristics are shown in Table 1.

Table 1. Borehole Characteristics

\begin{tabular}{cc}
\hline Parameter & Value \\
\hline \hline Ground thermal conductivity $(\mathrm{W} / \mathrm{m}-\mathrm{K})$ & 2 \\
Ground thermal diffusivity $\left(\mathrm{m}^{2} / \mathrm{s}\right)$ & $1 \mathrm{e}-06$ \\
Undisturbed ground temperature $\left({ }^{\circ} \mathrm{C}\right)$ & 10 \\
Borehole radius $(\mathrm{m})$ & 0.075 \\
Buried depth $(\mathrm{m})$ & 4 \\
Cross-sectional borehole thermal resistance $(\mathrm{m}-\mathrm{K} / \mathrm{W})$ & 0.15 \\
\hline
\end{tabular}

The basic configuration without any heat injection in the ground requires a borehole length of 198 meters to avoid the use of any auxiliary heating over the first 5 years of operation. To measure the impact of the proposed MPC strategy, a reduction of $16.7 \%$ to a length of 165 meters is attempted. Figures 6 and 7 compare the resulting total power consumption of the base configurations with those of the proposed assisted configuration. The power consumption values shown are time-averaged values which vary continuously throughout the simulation. Because of the load 
aggregation procedure, no time step is ever longer than 1 hour.



Figure 6 Power consumption over 5 years

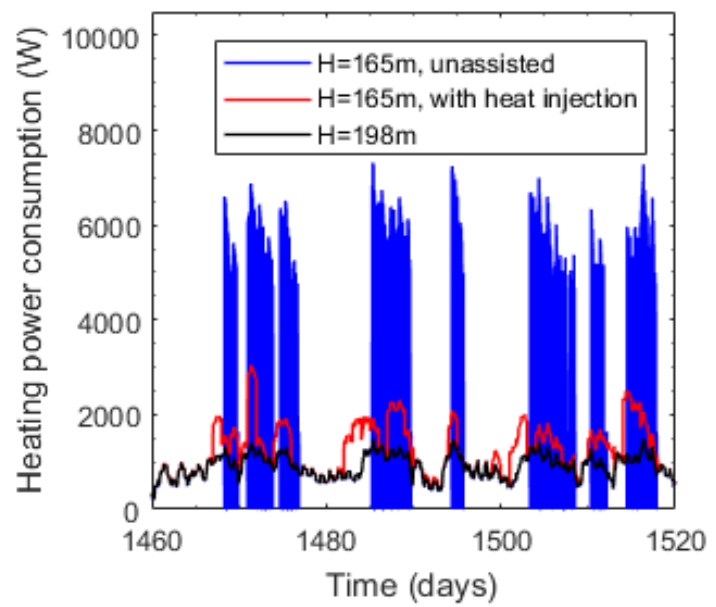

Figure 7 Power consumption during the $5^{\text {th }}$ heating season

The total heating power consumption (the heat pump compressor when operating in heating mode as well as the auxiliary heating) thus increases substantially with the reduced borehole length when no thermal assistance is used, which is representative of the energy performance penalty associated with an undersized GSHP system. The new control strategy applied with the self-assisted GSHP over 5 years allows to greatly reduce this performance penalty with a minimal increase in total energy consumption. Specifically, results show a $58 \%$ reduction in the peak power consumption over 5 years and an increase of $2.8 \%$ in the total energy consumption over the $5^{\text {th }}$ year compared to the undersized and unassisted configuration. Compared to the fully sized configuration, the $5^{\text {th }}$ year energy consumption thus increases from $11 \%$ to $14 \%$. The self-assisted GSHP completely eliminates the use of auxiliary electric heating over the first 5 years. Compared to the initial configuration with a depth of 198 meters, this means that the penalty on peak power consumption caused by the undersized borehole decreases from $488 \%$ to $204 \%$. Detailed results are shown in Table 2.

Figure 8 shows the injection pattern over 5 years. The injection pattern found to be optimal by the controller involves beginning heat injection typically 3 or 4 days before the beginning of the peak period, with injection periods often coinciding with local peak loads. This behaviour is displayed in Figure 9, where the periods of auxiliary heating with the unassisted configuration are used to indicate the approximate location of peaks for the assisted configuration.

Table 2. Comparison of three configurations

\begin{tabular}{|c|c|c|c|c|}
\hline Result & (units) & $\begin{array}{l}\text { Base configuration } \\
\text { (full size borehole) }\end{array}$ & $\begin{array}{c}\text { Undersized borehole } \\
\text { - unassisted } \\
\end{array}$ & $\begin{array}{c}\text { Undersized borehole } \\
- \text { self-assisted } \\
\end{array}$ \\
\hline Borehole length & $(\mathrm{m})$ & 198 & 165 & 165 \\
\hline Peak total power usage over 5 years & (W) & 1499 & 7320 & 3056 \\
\hline $\begin{array}{l}\text { Peak total power usage increase } \\
\text { relative to base config. }\end{array}$ & $(-)$ & - & $488 \%$ & $204 \%$ \\
\hline Peak heat pump usage over 5 years & $(\mathrm{W})$ & 1499 & 1640 & 1637 \\
\hline Peak aux. heating over 5 years & (W) & 0 & 5687 & 0 \\
\hline Peak heat injection over 5 years & (W) & 0 & 0 & 1662 \\
\hline Total energy consumption ( $5^{\text {th }}$ year) & $(\mathrm{kWh})$ & 3532 & 3928 & 4039 \\
\hline $\begin{array}{l}\text { Total energy consumption increase } \\
\text { relative to base config. ( } 5^{\text {th }} \text { year) }\end{array}$ & $(-)$ & - & $11 \%$ & $14 \%$ \\
\hline
\end{tabular}




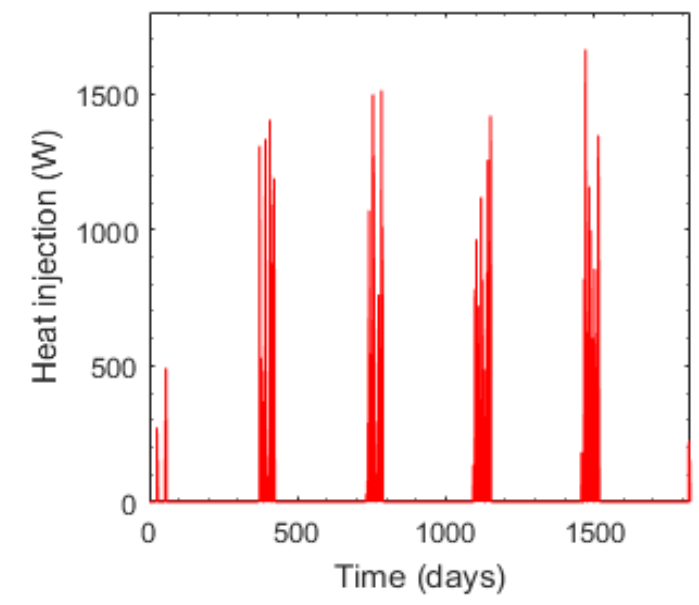

Figure 8 Heat injection over 5 years

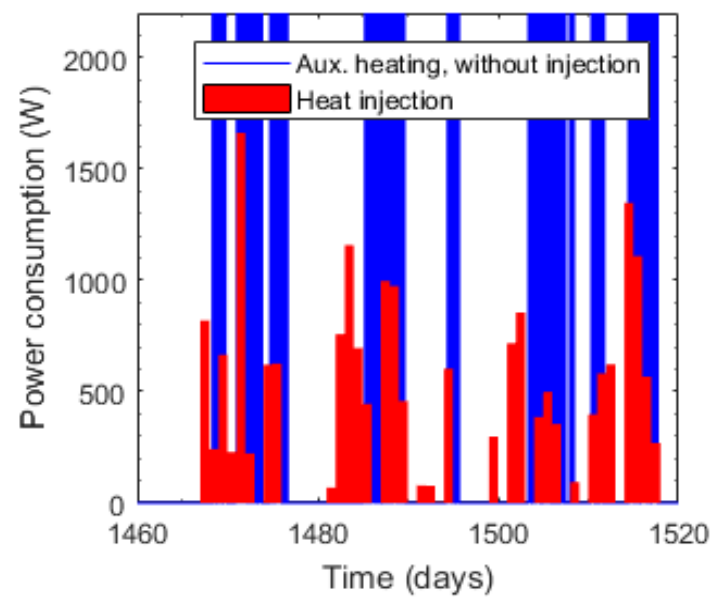

Figure 9 Heat injection during the $5^{\text {th }}$ heating season

\section{CONCLUSION}

This study presents a control strategy for a residential self-assisted GSHP operating in a cold climate which aims to reduce peak power consumption while minimizing energy consumption, thereby reducing the penalty suffered by shorter boreholes with regards to their energy performance. To do so, a simulation model was developed in the Modelica language, which includes an improvement to a load-shifting aggregation scheme. A model predictive controller with a receding horizon of 7 days was used to optimize a heat injection pattern per day over a simulation period of 5 years. This controller was used with a borehole undersized by $16.7 \%$ and removed all auxiliary electric power usage. Total peak power consumption was reduced by $58 \%$ compared to the same borehole used without any thermal assistance. This reduction comes at a cost of an increased annual energy consumption of $2.8 \%$.

These results indicate that self-assisted GSHPs offer potential to reduce required borehole lengths, thereby decreasing installation costs, which are an obstacle to the development of GSHPs. Future work will be required to quantify the impact of some of the assumptions made in the present study. The heat pump model will be modified to consider the dynamic operation of the system, rather than its time-averaged behavior. The borehole model will be modified to account for the short term heat transfer inside the borehole. As for the controller, future work will include the uncertainty of forecasted weather conditions in the MPC strategy. Furthermore, other MPC strategies, such as state space methods, will be considered for future use to reduce computation times.

\section{ACKNOWLEDGMENTS}

The second author received a start-up subsidy from the Fonds de recherche du Québec - Nature et Technologie.

\section{NOMENCLATURE}

$$
\begin{array}{ll}
C O P & =\text { Coefficient of performance } \\
g & =\text { Borehole "g-function" } \\
b & =\text { Borehole thermal response }(\mathrm{m}-\mathrm{K} / \mathrm{W}) \\
k_{s} & =\text { Soil thermal conductivity }(\mathrm{W} / \mathrm{m}-\mathrm{K}) \\
P L F & =\text { Part load factor }
\end{array}
$$

$$
\begin{array}{ll}
Q, \bar{Q}_{p} & =\text { Heat transfer rate }(\mathrm{W}), \text { instant and average } \\
T_{b} & =\text { Borehole wall temperature }\left({ }^{\circ} \mathrm{C}\right) \\
T_{g} & =\text { Ground temperature }\left({ }^{\circ} \mathrm{C}\right) \\
\Delta h & =\text { Thermal response factor increment } \\
\Delta t_{\text {agg }} & =\text { Aggregation time step }(\mathrm{s})
\end{array}
$$




\section{REFERENCES}

Afram, A. and Janabi-Sharifi, F. 2014. Theory and applications of HVAC control systems - A review of model predictive control (MPC). Building and Environment(72): 343-355.

ASHRAE. 2013. 2013 ASHRAE Handbook - Fundamentals (SI Edition). American Society of Heating, Refrigeration, and Air Conditioning Engineers. Atlanta, GA.

Claesson, J. and Javed, S. 2012. A load-aggregation method to calculate extraction temperatures of borehole heat exchangers. ASHRAE Transactions 118(1): 530-539.

Eskilson, P. 1987. Thermal analysis of heat extraction boreholes, Ph.D. thesis, Lund University.

Eslami-nejad, P. and Bernier, M. 2011. Coupling of geothermal heat pumps with thermal solar collectors using double U-tube boreholes with two independent circuits. Applied Thermal Engineering 31(14-15): 3066-3077.

Eslami Nejad, P., Cimmino, M. and Hosatte-Ducassy, S. 2017. Heat Pump Capacity Effects on Peak Electricity Consumption and Total Length of Self- and Solar-assisted Shallow Ground Heat Exchanger Networks. IGSHPA Technical/Research Conference and Expo 2017. Denver, USA. March 14-16.

Han, Z., Zheng, M., Kong, F., Wang, F., Li, Z. and Bai, T. 2008. Numerical simulation of solar assisted ground-source heat pump heating system with latent beat energy storage in severely cold area. Applied Thermal Engineering 28(11-12): 1427-1436.

Henderson, H., Huang, Y. J. and Parker, D. 1999. Residential Equipment Part Load Curves for Use in DOE-2. Lawrence Berkeley National Laboratory Report 42175.

Hendron, R. 2005. Building America Research Benchmark Definition, Version 3.1, Updated July 14, 2004. National Renewable Energy Laboratory Report NREL/TP-550-36429.

Kjellsson, E., Hellström, G. and Perers, B. 2010. Optimization of systems with the combination of ground-source heat pump and solar collectors in dwellings. Energy 35(6): 2667-2673.

Oldewurtel, F., Parisio, A., Jones, C. N., Gyalistras, D., Gwerder, M., Stauch, V., Lehmann, B., and Morari, M. 2012. Use of model predictive control and weather forecasts for energy efficient building climate control. Energy and Buildings(45): 15-27.

Pinel, P. 2003. Amélioration, validation et implantation d'un algorithme de calcul pour évaluer le transfert thermique dans les puits verticaux de systèmes de pompes à chaleur géothermiques, M.A.Sc. thesis, École Polytechnique de Montréal.

Shaikh, P. H., Nor, N. B. M., Nallagownden, P., Elamvazuthi, I. and Ibrahim, T. 2014. A review on optimized control systems for building energy and comfort management of smart sustainable buildings. Renewable and Sustainable Energy Reviews(34): 409-429.

Transition Énergétique Québec. 2017. Exigences techniques Novoclimat 2.0 - Maison et petit bâtiment multilogement. Available online at: http://www.transitionenergetique.gouv.qc.ca/en/business-clientele/construction-residentielle/novoclimat20/maisons/documents-techniques-et-formulaires/\#

Wetter, M., Fuchs, M., Grozman, P., Helsen, L., Jorissen, F., Müller, D., Nytsch-Geusen, C, Picard, D., Sahlin, P., and Thorade, M. 2015. IE A EBC annex 60 modelica library - an international collaboration to develop a free open-source model library for buildings and community energy systems. 14th International Conference of the International Building Performance Simulation Association. Hyderabad, India. December 7-9. 